\title{
Introducing emergency dental kits into Edmonton hospitals
}

\author{
Kevin Lobay, BSc, DMD, MD, GPR
}

A $s$ a fourth-year emergency medicine resident in Edmonton, I was recently involved in a project that introduced emergency dental kits into several of our hospitals. Having worked as a hospital dentist previously, I was aware of the need for a simple dental kit in the emergency department. I assembled a list of products that are necessary for treating routine dental emergencies and contacted a local distributer of dental materials. The supplier replied with a price list, which I forwarded to the chiefs of the various emergency departments in Edmonton. These materials are now assembled in small plastic containers and stored in the ear, nose and throat rooms of our emergency departments. Summarized below are the contents of our emergency dental kits along with descriptions of how these contents are used:

- Disposable dental mirrors are used to examine the dentition for any injures.

- Cotton rolls are placed adjacently to the chipped tooth to keep it dry.

- Wax mixing pads and disposable plastic spatulas are used to mix dental materials. Disposable plastic instruments are used to place the materials on the tooth surface.

- Dycal (calcium hydroxide cement, Dentsply Ltd.) is supplied in 2 small tubes. The cement is mixed, then placed over exposed pulp to encourage reparative dentin formation and hopefully to prevent the tooth from requiring a root canal treatment.

- GC Fuji 1 (glass ionomer cement, GC Europe) is supplied as a powder and liquid. These are mixed and then placed over exposed dentin to reduce the sensitivity of a chipped tooth.
- Various hemostatic dressings can be used to control bleeding from an extraction site. HemCon dental dressings (HemCon Medical Technologies Inc.) are miniature versions of the hemostatic dressings that are used by the military. Gelfoam gauze (Pfizer, Inc.) or Spongostan dental (Johnson \& Johnson) are ideal as dental packing material for hemorrhage following tooth avulsion or extraction. Spongostan dental is unique in that it is provided in separately packaged 1-cm cubes. My practice is to first place a hemostatic dressing such as HemCon into the bleeding socket, then place Gelfoam on top. A figure-of-eight resorbable suture can then be placed over the site to secure the packing in place.

- Our kits do not include any materials for splinting loose teeth. My opinion is that a dentist should be involved when splinting is required.

To explain the use of these materials to the emergency medicine community in Edmonton, I presented a brief lecture at our academic half-day and distributed my presentation via email and through our local resident website. I'm optimistic that these kits will help to improve patient care in our emergency departments. If you do not have such material in your own emergency department or program, feel welcome to use these suggestions to set up a similar dental kit where you are practising.

Competing interests: None declared.

Keywords: dental trauma, dental emergency, dental fracture, dental pain, oral trauma, emergency dental kit

Correspondence to: Dr. Kevin Lobay; klobay@gmail.com

Department of Emergency Medicine, University of Alberta, Edmonton, Alta.

Submitted Oct. 9, 2009; Accepted Oct. 20, 2009

This article has not been peer reviewed.

CJEM 2010;12(1):73 